\title{
3 Research Square

\section{Construction of An Index System of Core Competence Assessment For Infectious Disease Specialist Nurse: A Delphi Study}

Chao Wu

Air Force Medical University

Ping Wu

Huazhong University of Science and Technology

Pei Li

Tang Du Hospital

Feixia Cheng

Naval University of Engineering

Shizhe He

Air Force Medical University

Yanling Du

Air Force Medical University

Lang Hongjuan ( $0906963251 @ q q . c o m$ )

Air Force Medical University

\section{Research Article}

Keywords: Delphi method, index system, core competence, infectious disease specialist nurse

Posted Date: March 1st, 2021

DOl: https://doi.org/10.21203/rs.3.rs-244590/v1

License: (9) This work is licensed under a Creative Commons Attribution 4.0 International License.

Read Full License

Version of Record: A version of this preprint was published at BMC Infectious Diseases on August 10th, 2021. See the published version at https://doi.org/10.1186/s12879-021-06402-2. 


\section{Abstract}

Aim and objective: To establish an index system for the evaluation of infectious disease specialist nurse core competence.

Background: An index system for the evaluation of infectious disease specialist nurse core competence has not been established.

Design: A two-round Delphi survey sought opinions from experts about the index system for the evaluation of infectious disease specialist nurse core competence.

Methods: Based on the methods of literature retrieval, theoretical analysis and qualitative research, the draft of core competence evaluation index system of infectious disease specialist nurses was constructed. A Delphi survey was used for the study of 30 infectious disease experts from 8 provinces and cities around China. A modified recommendation for the Conducting and Reporting of Delphi studies (CREDES) was used to guide this study. A STROBE checklist was used.

Results: The evaluation index system of core competence of diseases specialist nurses is composed of 6 primary indicators which includes Nursing Abilities for infectious diseases, Infection Prevention and Control Capabilities, Capabilities in Response to Infectious Disease, Professional Development Capabilities, Communication and Management Capabilities and Professionalism and Humanistic Accomplishment, 16 secondary indicators and 47 tertiary indicators. The authority coefficient, judgment coefficient and familiarity degree of Delphi experts were $0.923,0.933$ and 0.913 respectively.

Conclusions: The evaluation index system of core competence of diseases specialist nurses is scientific and reliable. It can be reference for future training and assessment of infectious disease specialist nurses.

Relevance to clinical practice: Infectious disease specialist nurses are the main force for infectious disease nursing. Their core competence is related to the quality of infectious disease nursing and treatment. The core competence of the nurses is important for identification of training strategies and can be regarded as reference for nurse assessment and promotion. The construction of the index system is based on the consensus of infectious disease experts, which is helpful to standardize the training strategies and selection standards of infectious disease specialist nurses in the future and meet the needs of clinical infectious disease nursing.

\section{Introduction}

Infectious diseases have existed in human life for a very long time. In recent years, under the background of globalization and economic and cultural exchanges, public health emergencies of infectious diseases occur from time to time (Pitrelli \& Sturloni, 2007). Especially after the outbreak of Corona Virus Disease 2019 (COVID-19), the pandemic spreads rapidly all over the world in a short period of time, which poses 
great threats to the health and property safety of all human beings (Rauch, Jasny, Schmidt, \& Petsch, 2018; Triggle, Bansal, Farag, Ding, \& Sultan, 2020). The importance of medical treatment and nursing of infectious diseases has become increasingly prominent (Jump et al., 2018). The medical staff of infectious diseases department play a critical role in containing the spread of infectious diseases and treating infected patients (Houghton et al., 2020).

In clinical nursing work, specialist nurses are the leading figures in specialist nursing team, and their core competence level concerns the quality of the nursing and the development of the nursing career (Jokiniemi, Pietilä, \& Mikkonen, 2020; Rauch et al., 2018). Infectious disease specialist nurses are registered nurses who are are able to undertake and guide clinical infectious diseases nursing work since they have undergone systematic and standardized training with professional knowledge and specialist practical skills of infectious disease, communication and management capabilities and teaching and coaching skills.

Core competence was first applied in the field of enterprise management (Chiu, Chu, \& Kuo, 2019). It refers to the technology and knowledge that employees need to possess in the process of enterprise development. This concept was later applied to the field of nursing, which refers to the knowledge, skills and attitude that a nurse must possess in clinical nursing work (Taskiran \& Baykal, 2019; Wei, Niu, \& Ge, 2019). In respond to the growing complexity and rapid change of infectious diseases, the core competence of infectious disease specialist nurses should also be constantly enriched and improved. A competent infectious disease specialist nurse should not only need to acquire the professional knowledge and skills to provide systematic, safe and ethical holistic care for infectious disease patients, but also have the capabilities of safety protection and be able to respond to infectious disease emergencies.

\section{Background}

At present, there are some researches on the core competencies of diabetes specialist nurses (Xing et al., 2019), gastroenterology specialist nurses (Ren et al., 2019) and wound care specialist nurses (Eskes et al., 2014) et al. However, there is no research on the core competence of infectious disease specialist nurses. Nowadays, the clinical evaluation of core competence of infectious disease nurses is mostly based on subjective assessment which lacks systematic and objective standards. It is not conducive to the standardized development of infectious disease specialist nurses.

In consideration of the complexity and uncertainty of infectious diseases and the increasing of the incidence of transfusion transmitted diseases, the incidence of occupational exposure and injury among nursing personnel maintained an upward trend. This put forward higher requirements for the abilities of nurses in infectious diseases department. The aim of this study was to establish an index system for evaluation of infectious disease specialist nurse core competence.

\section{Methods}


A Delphi study was conducted with 30 participants from 12 hospitals in 8 different provinces and cities in China to explore their altitude to the index system for the core competence of infectious disease specialist nurses. A modified recommendation for the Conducting and Reporting of Delphi studies (CREDES) was used to guide the study (Heuzenroeder, Ibrahim, Khadka, Woodman, \& Kitson, 2020; Jünger, Payne, Brine, Radbruch, \& Brearley, 2017).

\subsection{Design}

Delphi survey is a feedback anonymous inquiry method. Its involves multiple rounds of consultation by using questionnaires to collect and summarize the questions to be asked after obtaining the opinions of experts until a consensus is reached (Campos-Luna, Miller, Beard, \& Leach, 2019). This independent way of consultation can ensure that there is no interference between experts (Black, Matthews, \& Millington, 2018). Therefore, it is a very effective method to set goals, items, etc. We set up a research group which is composed of one professor, one associate professor, two lecturers, one supervisor nurse and one postgraduate. The research group is responsible for literature review, theoretical analysis, selection of inquiry experts, compilation and distribution of inquiry questionnaires, sorting out and analyzing suggestions and data.

\subsection{Inclusion criteria}

The inclusion criteria of consultation experts participating in the investigation were as follows: (a) engaged in clinical nursing or medical work of infectious diseases, and working years in this field are more than 15 years; (b) worked with Medium-grade professional title and above; (c) should have bachelor degree or above; (d) voluntarily participate in the investigation, and ensure to participate in two rounds of consultation.

\subsection{Construction an evaluation index system}

We looked up literature about specialist nurses, infectious diseases, core competence and other related aspects (Chan, Lockhart, Schreiber, \& Kronk, 2020; Persson, Engström, Burström, \& Juuso, 2019; Weber, Rutala, Fischer, Kanamori, \& Sickbert-Bennett, 2016) and the core competence theory (Lavoie et al., 2018). On the basis of the above literature review after discussion, our research group carried out qualitative interviews with infectious disease experts, specialist nurses and patients. We finally set up 6 primary indicators (namely, disease management ability, infection prevention and control ability, emergency response ability, professional development ability, communication management ability and professional humanistic quality), 17 secondary indicators and 48 tertiary indicators.

\subsection{The first draft of the expert consultation questionnaire}

The questionnaire consists of three parts: (a) general information of experts: age, working years, education background, professional title, etc.; (b) evaluation index system of core competence of infectious disease specialist nurses expert consultation form: the importance of the index was evaluated by way of Likert 5-level scoring method, $5=$ very important, $4=$ important, $3=$ general, $2=$ unimportant, 1 
= completely unimportant, and the column for suggestions was provided; (c) expert familiarity with the content of the survey, and index judgment.

\subsection{Delphi consulting and feedback cycle}

Firstly, after introducing the subject to experts and obtaining informed consent, we sent the questionnaire to experts in the field of infectious diseases by email. Experts scored and modified the index items, and then returned the evaluation by email. Delphi method ensured the independence of opinions. We sorted out and summarized the experts' opinions and designed the questionnaire for the second round. The index inclusion criterion: Mean value assignment $>4.5$; coefficient of variation $<3$. If the importance score is between 3.5 and 4.5 , the research team needed to discuss and decide whether the indicator items needed to be retained or deleted (Shen et al., 2019). In the second round of Delphi expert consultation, the opinions of all experts tended to be the same, the evaluation index system was confirmed.

\subsection{Ethical consideration}

Our research was approved by the ethics committee and was conducted under ethical guidelines described in the Helsinki Declaration (World Medical Associationヌ2013). Before the investigation, we explained the purpose to the experts, and asked for their verbal consent before conducting the survey. During the investigation, participants could terminate and withdraw from the investigation at any time and the questionnaire was completed anonymously.

\subsection{Quality Control}

In order to ensure the research results were representative and reliable, we had proposed some basic requirements in selecting appraisal expert, and selected 30 infectious disease experts from 8 different provinces and cities in China. The research group collated and summarized the experts' opinions. In the data analysis, we made use of Kendall coordination coefficient and chi square value to test the significance of the expert's opinions, so as to ensure the reliability of the results.

\subsection{Statistical analysis}

SPSS 24.0 statistical software were used for data analysis. Measurement data and counting data were expressed in the form of mean \pm standard deviation and frequency, percentage respectively. The positive degree of experts was expressed in the form of questionnaire recovery rate. The expert authority coefficient ( $\mathrm{Cr}$ ) was the average value of expert familiarity with the indicators (Cs) and judgment criteria for the indicators (Sutherland, Yeung, Mak, \& Levesque, 2020). The coordination degree of expert opinions was expressed by Kendall harmony coefficient.

\section{Results}

\subsection{Basic information of experts}


Among the experts participating in the consultation, 23 (76.67\%) were infectious disease nursing experts, and 7 (23.33\%) were infectious disease medical experts. Their age ranged from 36 to 56 years old, with an average age of 46.27 (SD 5.99). Their working years ranged from 15 to 38 years, with an average working time of 25.27 (SD 5.92) years. There were 8 (26.67\%) with bachelor's degree, 16 (53.33\%) with master's degree and 6 (20\%) with doctor's degree (Table 1).

\subsection{Experts' enthusiasm}

The enthusiasm of the experts was assessed on the basis of the rate of the recovery rate of questionnaires. In the first round, 32 questionnaires were distributed and 30 effective questionnaires were received, with a recovery rate of $93.75 \%$; in the second round, 30 questionnaires were distributed and all of them were recovered, with a recovery rate of $100 \%$ (Table 2 ).

\subsection{Expert authority coefficient and opinion coordination degree}

The judgment coefficient, familiarity coefficient and authority coefficient are $0.933,0.913$ and 0.923 respectively, which meet the standard of expert consultation authority coefficient $>0.7$. In the first round of expert consultation, the Kendall's concordance coefficients of the first, second and third level indicators were $0.156,0.262$ and 0.318 respectively. In the second round of expert consultation, the Kendall's concordance coefficients of the first, second and third level indicators were $0.177,0.236$ and 0.324 respectively. And the Kendall's W test had statistical significance (all $p<0.01$ ) (Table 3 ).

\subsection{The index system of core competence assessment for infectious disease specialist nurse}

In this study, we adopted two rounds of consultation with the use of the Delphi method, involving a total of 30 experts from 8 provinces and cities including Shaanxi, Chongqing, Beijing, Zhejiang, Yunnan, Shandong, Hubei and Shanxi. In round 1, the research team modified 12 index, deleted 3 index, merged 3 index, added 2 index, adjusted 2 index based on the exclusion criterion and experts' opinions. In round 2 , the research team modified 2 index. Finally, the index system of core competence assessment for infectious disease specialist nurse was established and it included 6 first level indexes, 16 second level indexes and 47 third level indexes. The first level indicators referred to Nursing Abilities for infectious diseases, Infection Prevention and Control Capabilities, Capabilities in Response to Infectious Disease, Professional Development Capabilities, Communication and Management Capabilities and Professionalism and Humanistic Accomplishment. In the terms of weight, Infection Prevention and Control Capabilities showed the highest value (0.172), followed by Nursing Abilities for infectious diseases (0.169), while Professionalism and Humanistic Accomplishment showed the smallest value (0.161). Among the secondary indicators, Safety Protection Capabilities and Humanistic Care showed the highest value (0.065), while Prediction and Reporting showed the smallest value (0.058) (Table 4).

\section{Discussion}

\subsection{Reliability of Delphi expert consultation results}


In this study, a total of 30 experts engaged in clinical infectious disease treatment and nursing work participated in Delphi consultation who came from 8 different provinces and cities in China, which ensured the results were objective and would not be affected by the region. The consulting experts had been engaged in infectious diseases for more than 15 years, who had rich experience in clinical infectious diseases, and were familiar with the research contents. The authority coefficient of this research was 0.923, which showed that it had good authority. The response rates of the two rounds of expert consultation were $93.75 \%$ and $100 \%$ respectively, indicating that they had high enthusiasm. The Kendall's concordance coefficient of the two rounds of consultation were statistically significant, and the results of the evaluation index system of core competence of infectious disease specialist nurses were reliable.

\subsection{Importance of evaluation index system of core competence of infectious disease specialist nurses}

Infectious disease specialist nurses are the backbone of infectious disease nursing. Their core competence is related to the work quality, service level and team development of infectious disease nursing. At present, there is no research on the core competence index system of infectious disease specialist nurses, so the definition of the core competence of infectious disease specialist nurses is not clear. In the context of the New Coronavirus disease and the increasing number of new infectious diseases (Tanzi, Alquati, Martucci, \& De Panfilis, 2020; Xue, Cao, \& Wan, 2021), speeding up the training of infectious disease specialist nurses and clarifying their core competencies will help standardize the work of infectious disease nursing, improve the quality of nursing services, and prevent the spread of infectious diseases. Therefore, it is of great practical significance to construct the evaluation index system of core competence of infectious disease specialist nurses.

\subsection{Comprehensiveness of evaluation index system of core competence of infectious disease specialist nurses}

\subsubsection{Nursing Abilities for infectious diseases}

Infectious diseases are susceptible, transmissible, widespread and harmful (Keesing et al., 2010; Kiely et al., 2017). The management of infectious diseases is the basic responsibility of specialist nurses, and also one of the most important core competencies. In this study, the weight coefficient of infectious disease nursing ability was 0.169 , ranking second in the first level indicators, only to the ability of infection prevention and control capabilities, indicating that this ability is highly recognized by experts and very important. Infectious disease specialist nurses should be familiar with the knowledge of infectious diseases and commonly used drugs. They should be able to formulate corresponding nursing plans in response to different infectious disease patients and implement different nursing measures accordingly. At the same time, specialist nurses should also master first-aid nursing methods for patients with infectious diseases, make clear the requirements of specimen collection and the terminal treatment methods for patients with infectious diseases.

\subsubsection{Infection Prevention and Control Capabilities}


Infection prevention and control ability is the most important core ability of infectious disease specialist nurses, and it is an important guarantee of continuous work (Cho \& Chung, 2017; Fadare, Akpor, Ifechukwude, Richard, \& Bello, 2020; Tschudin-Sutter et al., 2018). It is reported that the risk of infectious diseases of nurses in infectious diseases department is much higher than that of ordinary clinical nurses (Fadare et al., 2020). The importance of infection prevention and control ability in this study ranked the first, with the weight coefficient of 0.172 . The secondary indexes were safety protection capabilities and disinfection and quarantine skills, with safety protection capabilities as the largest weight. In the clinical infectious disease nursing work, nurses in the infectious disease department should put self-protection in the first place.

\subsubsection{Capabilities in Response to Infectious Disease}

The capabilities in response to infectious disease of infectious disease specialist nurses refers to the ability of emergency rescue and nursing in public health emergencies. Public health emergencies of infectious diseases spread widely, spread rapidly and do great harm (Morens \& Fauci, 2020). Therefore, as a specialist nurse of infectious diseases, it is necessary to have the ability of emergency response and the ability to predict the emergency of infectious diseases. In their daily work, they need to master the reporting time limit of legal infectious diseases, and be familiar with the reporting and drilling process and relevant regulations of public health emergencies of infectious diseases. In the clinical nursing work of New Coronavirus disease, infectious disease specialist nurses played an important role in the outbreak of disease (Lee \& Lee, 2020).

\subsubsection{Professional Development Capabilities}

Infectious disease nursing is a profession that keeps pace with the times. Facing the continuous variation and evolution of the virus, the specialist nurse needs to have the ability of professional development. The ability 'to train other nurses in face of emerging infectious diseases emergencies' and 'to improve and innovate on infectious disease nursing process and protective articles' accounted for the largest weight, which were 0.022 . In public health emergencies of infectious diseases, it is of great significance for infectious disease specialist nurses to help ordinary nurses to work quickly according to the standardized training process, so as to enhance and expand the nursing reserve force (Lam, Kwong, Hung, \& Chien, 2020; Tan et al., 2020) and innovation is an important driving force to promote clinical nursing work (Albert, 2018). At the same time, as a specialist nurse of infectious diseases, it is also necessary to master the frontier dynamic knowledge, have the ability of further teaching and learning, and promote the professional development and the improvement of their own ability.

\subsubsection{Communication and Management Capabilities}

In clinical nursing work, good communication and management skills are essential (Curtis et al., 2013; Grubaugh \& Flynn, 2018). Due to the particularity of patients with infectious diseases, they are more sensitive, so in the process of communication with patients with infectious diseases or their families, nurses should pay attention to the skills, contents and methods of communication (Gaur et al., 2020). In 
the second level indicators, the score of management ability accounts the highest. Specialist nurses are different from ordinary nurses. They need not only master basic nursing skills, but also assume the role of a manager.

\subsubsection{Professionalism and Humanistic Accomplishment}

Since infectious disease nursing work confronted with infectious diseases patients, the work is of a certain degree of risks. Therefore, infectious disease specialist nurses should have good professional humanistic accomplishment. They must recognize the occupation identity of infectious disease nursing work. Infectious disease nursing work is a high-risk occupation (Maltezou et al., 2020), so the nurses should have good self-adjusting ability to release the pressure of infectious disease nursing work. In the process of communication with infectious diseases patients, they should respect and treat everyone equally.

\section{Conclusion}

Through two rounds of Delphi expert consultation, the core competence index system of infectious disease specialist nurses was established, which entailed good authority, reliability and comprehensiveness. It can provide reference for the training and assessment of infectious disease specialist nurses in the future.

\section{Relevance to Clinical Practice}

In the context of the global New Coronavirus pneumonia pandemic, the importance of infectious disease nursing is increasing. As the backbone of nursing work, specialist nurses play an important role in nursing work. To clarify their core competence requirements is helpful to specify the content for the development of infectious disease specialist nurses and provide reference for their training and assessment.

\section{Declarations}

\subsection{Ethics approval and consent to participate}

Research was approved by the ethics committee of Tangdu Hospital of Air Force Military Medical University, China (Number TDLL2019-09-13). Informed consent was obtained from all participants included in the study.

\subsection{Consent for publication}

Written informed consent for publication was obtained from all participants.

\subsection{Availability of data and materials}


The datasets generated and analysed during the current study are not publicly available due to protect the privacy of consulting experts but are available from the corresponding author (906963251@qq.com) on reasonable request.

\subsection{Competing interests}

No potential conflict of interest was reported by the authors.

\subsection{Funding}

No Funding.

\subsection{Authors' contributions}

Chao Wu wrote the main manuscript text. Ping Wu distributed questionnaires to experts. Pei Li contributed to the analysis and processing of data. Feixia Cheng contributed to the writing and revision of articles. Yanling Du contributed to the design of index system. Shizhe He contributed to the distribution and collection of questionnaires. Hongjuan Lang contributed to the design of index system.

\subsection{Acknowledgements}

We would like to express gratitude to the infectious disease specialist for participating in this survey during the time out of their busy schedule.

\section{References}

1. Albert, N. M. (2018). Operationalizing a Nursing Innovation Center Within a Health Care System. Nurs Adm Q, 42(1), 43-53. doi:10.1097/naq.0000000000000266

2. Black, M., Matthews, L. R., \& Millington, M. J. (2018). Using an adapted Delphi process to develop a survey evaluating employability assessment in total and permanent disability insurance claims. Work, 60(4), 539-548. doi:10.3233/wor-182761

3. Campos-Luna, I., Miller, A., Beard, A., \& Leach, M. (2019). Validation of mouse welfare indicators: a Delphi consultation survey. Sci Rep, 9(1), 10249. doi:10.1038/s41598-019-45810-y

4. Chan, T. E., Lockhart, J. S., Schreiber, J. B., \& Kronk, R. (2020). Determining nurse practitioner core competencies using a Delphi approach. J Am Assoc Nurse Pract, 32(3), 200-217. doi:10.1097/jxx.0000000000000384

5. Chiu, M. C., Chu, C. Y., \& Kuo, T. C. (2019). Product service system transition method: building firm's core competence of enterprise. International Journal of Production Research, 57(20), 6452-6472. doi:10.1080/00207543.2019.1566670

6. Cho, S. Y., \& Chung, D. R. (2017). Infection Prevention Strategy in Hospitals in the Era of CommunityAssociated Methicillin-Resistant Staphylococcus aureus in the Asia-Pacific Region: A Review. Clin Infect Dis, 64(suppl_2), S82-s90. doi:10.1093/cid/cix133 
7. Curtis, J. R., Back, A. L., Ford, D. W., Downey, L., Shannon, S. E., Doorenbos, A. Z., . . Engelberg, R. A. (2013). Effect of communication skills training for residents and nurse practitioners on quality of communication with patients with serious illness: a randomized trial. Jama, 310(21), 2271-2281. doi:10.1001/jama.2013.282081

8. Eskes, A. M., Maaskant, J. M., Holloway, S., van Dijk, N., Alves, P., Legemate, D. A., . . Vermeulen, H. (2014). Competencies of specialised wound care nurses: a European Delphi study. Int Wound J, 11(6), 665-674. doi:10.1111/iwj.12027

9. Fadare, R. I., Akpor, O. A., Ifechukwude, I. G., Richard, D. A., \& Bello, C. B. (2020). Nurses' Safety in Caring for Tuberculosis Patients at a Teaching Hospital in South West Nigeria. J Environ Public Health, 2020, 3402527. doi:10.1155/2020/3402527

10. Gaur, S., Pandya, N., Dumyati, G., Nace, D. A., Pandya, K., \& Jump, R. L. P. (2020). A Structured Tool for Communication and Care Planning in the Era of the COVID-19 Pandemic. J Am Med Dir Assoc, 21(7), 943-947. doi:10.1016/j.jamda.2020.05.062

11. Grubaugh, M. L., \& Flynn, L. (2018). Relationships Among Nurse Manager Leadership Skills, Conflict Management, and Unit Teamwork. J Nurs Adm, 48(7-8), 383-388. doi:10.1097/nna.0000000000000633

12. Heuzenroeder, L., Ibrahim, F., Khadka, J., Woodman, R., \& Kitson, A. (2020). A Delphi study to identify content for a new questionnaire based on the 10 Principles of Dignity in Care. $J$ Clin Nurs. doi:10.1111/jocn.15462

13. Houghton, C., Meskell, P., Delaney, H., Smalle, M., Glenton, C., Booth, A., . . Biesty, L. M. (2020). Barriers and facilitators to healthcare workers' adherence with infection prevention and control (IPC) guidelines for respiratory infectious diseases: a rapid qualitative evidence synthesis. Cochrane Database Syst Rev, 4(4), Cd013582. doi:10.1002/14651858.cd013582

14. Jokiniemi, K., Pietilä, A. M., \& Mikkonen, S. (2020). Construct Validity of Clinical Nurse Specialist Core Competency Scale: An Exploratory Factor Analysis. J Clin Nurs. doi:10.1111/jocn.15587

15. Jump, R. L. P., Crnich, C. J., Mody, L., Bradley, S. F., Nicolle, L. E., \& Yoshikawa, T. T. (2018). Infectious Diseases in Older Adults of Long-Term Care Facilities: Update on Approach to Diagnosis and Management. J Am Geriatr Soc, 66(4), 789-803. doi:10.1111/jgs.15248

16. Jünger, S., Payne, S. A., Brine, J., Radbruch, L., \& Brearley, S. G. (2017). Guidance on Conducting and REporting DElphi Studies (CREDES) in palliative care: Recommendations based on a methodological systematic review. Palliat Med, 31(8), 684-706. doi:10.1177/0269216317690685

17. Keesing, F., Belden, L. K., Daszak, P., Dobson, A., Harvell, C. D., Holt, R. D., . . Ostfeld, R. S. (2010). Impacts of biodiversity on the emergence and transmission of infectious diseases. Nature, 468(7324), 647-652. doi:10.1038/nature09575

18. Kiely, P., Gambhir, M., Cheng, A. C., McQuilten, Z. K., Seed, C. R., \& Wood, E. M. (2017). Emerging Infectious Diseases and Blood Safety: Modeling the Transfusion-Transmission Risk. Transfus Med Rev, 31(3), 154-164. doi:10.1016/j.tmrv.2017.05.002 
19. Lam, S. K. K., Kwong, E. W. Y., Hung, M. S. Y., \& Chien, W. T. (2020). Investigating the Strategies Adopted by Emergency Nurses to Address Uncertainty and Change in the Event of Emerging Infectious Diseases: A Grounded Theory Study. Int J Environ Res Public Health, 17(7). doi:10.3390/ijerph17072490

20. Lavoie, P., Michaud, C., Bélisle, M., Boyer, L., Gosselin, É., Grondin, M., . . Pepin, J. (2018). Learning theories and tools for the assessment of core nursing competencies in simulation: A theoretical review. J Adv Nurs, 74(2), 239-250. doi:10.1111/jan.13416

21. Lee, N., \& Lee, H. J. (2020). South Korean Nurses' Experiences with Patient Care at a COVID-19Designated Hospital: Growth after the Frontline Battle against an Infectious Disease Pandemic. Int J Environ Res Public Health, 17(23). doi:10.3390/ijerph17239015

22. Maltezou, H. C., Dedoukou, X., Tseroni, M., Tsonou, P., Raftopoulos, V., Papadima, K., ... Sipsas, N. (2020). SARS-CoV-2 Infection in Healthcare Personnel With High-risk Occupational Exposure: Evaluation of 7-Day Exclusion From Work Policy. Clin Infect Dis, 71(12), 3182-3187. doi:10.1093/cid/ciaa888

23. Morens, D. M., \& Fauci, A. S. (2020). Emerging Pandemic Diseases: How We Got to COVID-19. Cell, 182(5), 1077-1092. doi:10.1016/j.cell.2020.08.021

24. Persson, A. C., Engström, Å., Burström, O., \& Juuso, P. (2019). Specialist ambulance nurses' experiences of births before arrival. Int Emerg Nurs, 43, 45-49. doi:10.1016/j.ienj.2018.08.002

25. Pitrelli, N., \& Sturloni, G. (2007). Infectious diseases and governance of global risks through public communication and participation. Ann Ist Super Sanita, 43(4), 336-343.

26. Rauch, S., Jasny, E., Schmidt, K. E., \& Petsch, B. (2018). New Vaccine Technologies to Combat Outbreak Situations. Front Immunol, 9, 1963. doi:10.3389/fimmu.2018.01963

27. Ren, H., Liu, C., Wang, R., Zhang, M., Ma, F., Li, R., . . Li, L. (2019). Core Competencies Required for Gastroenterology Nursing Specialists in China. Gastroenterol Nurs, 42(2), 169-178. doi:10.1097/sga.0000000000000392

28. Shen, L., Yang, J., Jin, X., Hou, L., Shang, S., \& Zhang, Y. (2019). Based on Delphi method and Analytic Hierarchy Process to construct the Evaluation Index system of nursing simulation teaching quality. Nurse Educ Today, 79, 67-73. doi:10.1016/j.nedt.2018.09.021

29. Sutherland, K., Yeung, W., Mak, Y., \& Levesque, J. F. (2020). Envisioning the future of clinical analytics: a modified Delphi process in New South Wales, Australia. BMC Med Inform Decis Mak, 20(1), 210. doi:10.1186/s12911-020-01226-7

30. Tan, R., Yu, T., Luo, K., Teng, F., Liu, Y., Luo, J., \& Hu, D. (2020). Experiences of clinical first-line nurses treating patients with COVID-19: A qualitative study. J Nurs Manag, 28(6), 1381-1390. doi:10.1111/jonm.13095

31. Tanzi, S., Alquati, S., Martucci, G., \& De Panfilis, L. (2020). Learning a palliative care approach during the COVID-19 pandemic: A case study in an Infectious Diseases Unit. Palliat Med, 34(9), 1220-1227. doi:10.1177/0269216320947289 
32. Taskiran, G., \& Baykal, U. (2019). Nurses' disaster preparedness and core competencies in Turkey: a descriptive correlational design. Int Nurs Rev, 66(2), 165-175. doi:10.1111/inr.12501

33. Triggle, C. R., Bansal, D., Farag, E., Ding, H., \& Sultan, A. A. (2020). COVID-19: Learning from Lessons To Guide Treatment and Prevention Interventions. mSphere, 5(3). doi:10.1128/mSphere.00317-20

34. Tschudin-Sutter, S., Kuijper, E. J., Durovic, A., Vehreschild, M., Barbut, F., Eckert, C., . . Widmer, A. F. (2018). Guidance document for prevention of Clostridium difficile infection in acute healthcare settings. Clin Microbiol Infect, 24(10), 1051-1054. doi:10.1016/j.cmi.2018.02.020

35. Weber, D. J., Rutala, W. A., Fischer, W. A., Kanamori, H., \& Sickbert-Bennett, E. E. (2016). Emerging infectious diseases: Focus on infection control issues for novel coronaviruses (Severe Acute Respiratory Syndrome-CoV and Middle East Respiratory Syndrome-CoV), hemorrhagic fever viruses (Lassa and Ebola), and highly pathogenic avian influenza viruses, $\mathrm{A}(\mathrm{H} 5 \mathrm{~N} 1)$ and $\mathrm{A}(\mathrm{H} 7 \mathrm{~N} 9)$. Am J Infect Control, 44(5 Suppl), e91-e100. doi:10.1016/j.ajic.2015.11.018

36. Wei, W., Niu, Y., \& Ge, X. (2019). Core competencies for nurses in Chinese intensive care units: a crosssectional study. Nurs Crit Care, 24(5), 276-282. doi:10.1111/nicc.12398

37. Xing, Q., Zhang, M., Zhao, F., Zhou, Y., Mo, Y., \& Yuan, L. (2019). The Development of a Standardized Framework for Primary Nurse Specialists in Diabetes Care in China: A Delphi Study. J Nurs Res, 27(6), e53. doi:10.1097/jnr.0000000000000330

38. Xue, L., Cao, X., \& Wan, H. (2021). Releasing Wolbachia-infected mosquitos to mitigate the transmission of Zika virus. Journal of Mathematical Analysis and Applications, 496(1). doi:10.1016/j.jmaa.2020.124804

\section{Tables}

TABLE 1 Demographic information of experts 


\begin{tabular}{|c|c|c|}
\hline Project & Frequency $(\mathrm{N})$ & Proportion (\%) \\
\hline \multicolumn{3}{|l|}{ Age (years) } \\
\hline$₫ 40$ & 4 & 13.33 \\
\hline $40 \sim 50$ & 17 & 56.67 \\
\hline$\otimes 50$ & 9 & 30.00 \\
\hline \multicolumn{3}{|l|}{ Highest degree } \\
\hline Undergraduate & 8 & 26.67 \\
\hline Master's & 16 & 53.33 \\
\hline Doctorate & 6 & 20.00 \\
\hline \multicolumn{3}{|c|}{ Work experience in infectious disease (years) } \\
\hline$₫ 20$ & 7 & 23.33 \\
\hline 20 30 & 18 & 60.00 \\
\hline$\otimes 30$ & 5 & 16.67 \\
\hline \multicolumn{3}{|l|}{ Title } \\
\hline Medium-grade professional title & 5 & 16.67 \\
\hline Associate senior professional title & 17 & 56.67 \\
\hline Senior professional title & 8 & 26.66 \\
\hline \multicolumn{3}{|l|}{ Research field } \\
\hline Nursing of infectious disease & 23 & 76.67 \\
\hline Treatment of infectious diseases & 7 & 23.33 \\
\hline
\end{tabular}

TABLE 2 Recovery of the questionnaire and suggestions offered 


\begin{tabular}{|lll|}
\hline & First round & Second round \\
\hline Questionnaire recovery & & \\
\hline Number of questionnaires distributed & 32 & 30 \\
\hline Number of recycled questionnaires & 30 & 30 \\
\hline Rate of recovery (\%) & 93.75 & 100 \\
\hline Effective questionnaire & 30 & 30 \\
\hline Effective proportion & 100 & 100 \\
\hline Proposed ratio & & \\
\hline Number of experts & 19 & 2 \\
\hline Constituent ratio (\%) & 63.33 & 6.67 \\
\hline
\end{tabular}

TABLE 3 The result of expert opinions' coordination degree

\begin{tabular}{|llllll|}
\hline & Hierarchical level & Index(n) & CV/Kendall's $W$ & $X^{2}$ & $P$ \\
\hline Round 1 & First-level & 5 & 0.156 & 23.356 & 0.000 \\
& Second-level & 16 & 0.262 & 125.990 & 0.000 \\
\hline \multirow{2}{*}{ Round 2 } & Third-level & 47 & 0.318 & 448.490 & 0.000 \\
\cline { 2 - 4 } & Second-level & 5 & 0.177 & 26.579 & 0.000 \\
\hline & Third-level & 46 & 0.236 & 106.262 & 0.000 \\
\hline
\end{tabular}

TABLE 4 Core Competence Evaluation Index System of Infectious Disease Specialist Nurses 


\begin{tabular}{|c|c|c|c|}
\hline Index Level $1^{\text {st }}, 2^{\text {nd }}$ and $3^{\text {rd }}$ & $\begin{array}{l}\text { Significance } \\
\text { Grade }\end{array}$ & $\begin{array}{l}\text { Variable } \\
\text { Coefficient }\end{array}$ & $\begin{array}{l}\text { Weighting } \\
\text { Targets }\end{array}$ \\
\hline 1.Nursing Abilities for infectious diseases & $4.90 \pm 0.31$ & 0.062 & 0.169 \\
\hline 1.1 Theoretical knowledge & $4.87 \pm 0.35$ & 0.071 & 0.063 \\
\hline $\begin{array}{l}\text { 1.1.1Grasp the pathogenesis of common infectious } \\
\text { diseases and the relevant knowledge of diseases } \\
\text { including the historical epidemiology, the main nursing } \\
\text { points and health education }\end{array}$ & $4.67 \pm 0.55$ & 0.117 & 0.021 \\
\hline $\begin{array}{l}\text { 1.1.2 Be familiar with the basics such as the dosage } \\
\text { regimen, administration route, side effects and matters } \\
\text { needing attention of drugs which are commonly taken by } \\
\text { infectious diseases patients }\end{array}$ & $4.50 \pm 0.78$ & 0.173 & 0.020 \\
\hline 1.2 Operational skills & $4.83 \pm 0.38$ & 0.078 & 0.063 \\
\hline $\begin{array}{l}\text { 1.2.1 Be able to collect different samples such as blood } \\
\text { and nasopharyngeal swab from infectious diseases } \\
\text { patients }\end{array}$ & $4.87 \pm 0.35$ & 0.071 & 0.022 \\
\hline $\begin{array}{l}\text { 1.2.2 Be able to deal with the symptoms and signs of } \\
\text { common diseases such as fever, erythra, diarrhea, } \\
\text { twitching and seizure }\end{array}$ & $4.87 \pm 0.35$ & 0.071 & 0.022 \\
\hline $\begin{array}{l}\text { 1.2.3 Be familiar with the common diagnosis and } \\
\text { treatment in infectious disease departments such as } \\
\text { compression hemostasis for Sengstaken-Blakemore tube, } \\
\text { lactulose enema, and traumatic artetial blood pressure } \\
\text { supervision paracentesis. }\end{array}$ & $4.70 \pm 0.54$ & 0.114 & 0.021 \\
\hline $\begin{array}{l}\text { 1.2.4 Master the emergence care skills for critical } \\
\text { infectious diseases patients }\end{array}$ & $4.83 \pm 0.38$ & 0.078 & 0.022 \\
\hline 1.3 Critical Thinking capabilities & $4.90 \pm 0.31$ & 0.062 & 0.064 \\
\hline $\begin{array}{l}\text { 1.3.1 Be able to assess and observe the state of the } \\
\text { infectious diseases patients }\end{array}$ & $4.87 \pm 0.35$ & 0.071 & 0.022 \\
\hline $\begin{array}{l}\text { 1.3.2 Be able to predict and figure out the risk of } \\
\text { occurrence of the potential complications (such as } \\
\text { hepatic encephalopathy, esophagogastric variceal } \\
\text { bleeding and suffocation) }\end{array}$ & $4.80 \pm 0.41$ & 0.085 & 0.022 \\
\hline $\begin{array}{l}\text { 1.3.3 Be able to draw up nursing plans in accordance with } \\
\text { the different state of the different infectious diseases } \\
\text { patients }\end{array}$ & $4.87 \pm 0.35$ & 0.071 & 0.022 \\
\hline 2.Infection Prevention and Control Capabilities & $5.00 \pm 0.00$ & 0.000 & 0.172 \\
\hline 2.1 Safety Protection Capabilities & $5.00 \pm 0.00$ & 0.000 & 0.065 \\
\hline $\begin{array}{l}\text { 2.1.1 Be familiar with the Law on Prevention and Control } \\
\text { of Infectious Diseases of the People's Republic of China } \\
\text { and the Guidance to Protective Techniques for Health Care } \\
\text { Workers }\end{array}$ & $4.27 \pm 0.74$ & 0.173 & 0.019 \\
\hline
\end{tabular}

Page 16/19 
2.1.2 Be aware of the protective requirements for different kinds of infectious diseases

$\begin{array}{lll}4.90 \pm 0.31 \quad 0.062 & 0.022\end{array}$

2.1.3 Master the tactics of standard and extra precautions

$5.00 \pm 0.00 \quad 0.000 \quad 0.022$

2.1.4 Master the processes and methods of putting on the protective articles

$\begin{array}{lll}5.00 \pm 0.00 \quad 0.000 & 0.022\end{array}$

2.1.5 Master the skills and processes coping with

$\begin{array}{lll}4.97 \pm 0.18 & 0.037 & 0.022\end{array}$

professional exposure risks such as skin mucous

membrane and sharp instrument injury

2.2 Disinfection and Quarantine Skills

$4.97 \pm 0.18$

0.037

0.065

2.2.1 Be familiar with common physical and chemical disinfection

$\begin{array}{lll}4.80 \pm 0.41 \quad 0.085 & 0.022\end{array}$

2.2.2 Be able to correctly dispose of different medical wastes by infectious diseases patients (such as infectious

$4.70 \pm 0.54$

0.114

0.021 diarrhea, AIDS, COVID-19, etc.)

2.2.3 Master the disinfection methods of inpatient ward and instrument and equipment in infectious diseases department

2.2.4 Master the common isolation techniques and methods

2.2.5 Be aware of the requirements for different isolation techniques (isolation due to airborne transmission, contact transmission and droplet transmission)

3. Capabilities in Response to Infectious Disease $4.80 \pm 0.41$

0.085

0.166

3.1 Emergency Drills

$4.67 \pm 0.61$

0.130

0.061

3.1.1 Be familiar with National Emergency Plan for Medical and Health Rescue in Response to Public
$4.27 \pm 0.69$
0.162
0.019

Emergencies

$\begin{array}{llll}\text { 3.1.2 Take part in emergency drills for infectious diseases } & 4.40 \pm 0.72 & 0.165 & 0.020\end{array}$ emergencies in regular terms
3.2 Prediction and Reporting
$4.47 \pm 0.78$
0.174
0.058

3.2.1 Be able to predict and recognize the infectious diseases emergencies

$\begin{array}{lll}4.27 \pm 0.58 & 0.137 & 0.019\end{array}$

3.2.2 Master the reporting process of the infectious diseases emergencies

$\begin{array}{lll}4.70 \pm 0.47 & 0.099 & 0.021\end{array}$

\subsection{Response Capabilities}

$4.87 \pm 0.35$

0.071

0.063

3.3.1 Be familiar with the response process of the infectious diseases emergencies

$\begin{array}{lll}4.60 \pm 0.56 & 0.122 & 0.021\end{array}$

4.Professional Development Capabilities

$4.67 \pm 0.55$

0.117

0.161

4.1 Learning Abilities

$4.87 \pm 0.35 \quad 0.071$

0.063

Page 17/19 
4.1.1 Learn the cutting-edge dynamic knowledge on infectious diseases
$4.80 \pm 0.41$
0.085
0.022

4.1.2 Participate in knowledge training and academic exchanges activities on infectious diseases

$\begin{array}{lll}4.53 \pm 0.51 & 0.112 & 0.020\end{array}$

4.2 Teaching Abilities

$4.50 \pm 0.73$

0.162

0.059

4.2.1 Be able to conduct clinical teaching

$4.67 \pm 0.53$

0.113

0.021

4.2.2 Be able to conduct lectures

$4.57 \pm 0.63$

0.137

0.021

4.2.3 Be able to train other nurses in face of emerging infectious diseases emergencies

$\begin{array}{lll}4.87 \pm 0.35 & 0.071 & 0.022\end{array}$

4.3 Abilities in Scientific Researches and Inventions

$4.57 \pm 0.68$

0.149

0.059

4.3.1 Be able to select and design scientific researches

$4.60 \pm 0.62$

0.135

0.021

4.3.2 Be able to search and retrieve literature documents

$4.67 \pm 0.55$

0.117

0.021

by various ways and assess the quality of the literature

4.3.3 Be able to collect, analyze and process the relevant data

$\begin{array}{lll}4.60 \pm 0.68 & 0.147 & 0.021\end{array}$

4.3.4 Be able to write papers

$4.73 \pm 0.45$

0.095

0.021

4.3.5 Be able to improve and innovate on infectious disease nursing process and protective articles

$\begin{array}{lll}4.87 \pm 0.35 & 0.071 & 0.022\end{array}$

5.Communication and Management Capabilities

$4.80 \pm 0.41$

0.085

0.166

5.1 Communication Skills

$4.83 \pm 0.38$

0.078

0.063

5.1.1 Master the communication skills with infectious diseases patients and their families in consideration with

$4.83 \pm 0.38$

0.078

0.022 the patients' sensitivity, fear and other psychological characteristics

5.1.2 Be able to communicate effectively with other team members so as to improve the treatment

$\begin{array}{lll}4.80 \pm 0.41 \quad 0.085 & 0.022\end{array}$

5.2 Coordination Abilities

$4.70 \pm 0.60$

0.127

0.061

5.2.1 Be able to cope with disputes between nursing workers and patients

$\begin{array}{lll}4.67 \pm 0.48 & 0.103 & 0.021\end{array}$

5.2.2 Be able to cooperate with other medical workers and have the capability of organization
$4.70 \pm 0.54$
0.114
0.021

5.2.3 Be able to collaborate with other units and departments and effectively coordinate human and $4.60 \pm 0.62$

0.135

0.021 material resources, etc.

5.3 Management Abilities

5.3.1 Be able to distribute, guide, supervise and manage the infectious diseases nurses

$\begin{array}{lll}4.87 \pm 0.35 & 0.071 \quad 0.063\end{array}$

$\begin{array}{lll}4.83 \pm 0.38 & 0.078 & 0.022\end{array}$ 
5.3.2 Be able to manage materials such as drugs, consumable items, documents, instrument and equipment in infectious diseases department
5.3.3 Be able to evaluate and improve the quality of infectious diseases nursing issues and interventions

6. Professionalism and Humanistic Accomplishment

6.1 Professionalism

6.1.1 Be passionate about infectious diseases nursing and possess the sense of professional identity of nursing infectious diseases patients

6.1.2 Be capable of adjusting oneself and governing the stress in infectious diseases nursing work

\subsection{Humanistic Care}

6.2.1 Respect the patient and protect patients' privacy and show no discrimination to the patients

6.2.2 Be capable of providing psychological counseling and mental nursing

6.2.3 Be capable of providing health education for the infectious diseases patients and the public
$4.50 \pm 0.63$
0.140
0.020

$4.83 \pm 0.38$

0.078

0.022

$4.83 \pm 0.38$

0.078

0.167

$\begin{array}{lll}4.93 \pm 0.25 & 0.052 & 0.064\end{array}$

$\begin{array}{lll}4.90 \pm 0.31 & 0.062 & 0.022\end{array}$

$\begin{array}{lll}4.90 \pm 0.31 & 0.062 & 0.022\end{array}$

$\begin{array}{lll}4.93 \pm 0.25 & 0.052 & 0.022\end{array}$

$\begin{array}{lll}4.97 \pm 0.18 & 0.037 & 0.065\end{array}$

$\begin{array}{lll}4.90 \pm 0.31 & 0.062 & 0.022\end{array}$

$\begin{array}{lll}4.87 \pm 0.35 & 0.071 & 0.022\end{array}$

$\begin{array}{lll}4.87 \pm 0.35 & 0.071 & 0.022\end{array}$

